\title{
HEIDEGGER E SLOTERDIJK SOBRE A NOÇÃO DE “ESPAÇO INTERIOR” EM RILKE
}

\author{
Maurício Fernando Pitta (Mestrado em Filosofia Contemporânea - UEL) \\ mauriciopitta@hotmail.com \\ Prof. Dr. José Fernandes Weber (Orientador)
}

\section{RESUMO}

Visamos, nesta comunicação, ensaiar a aproximação das leituras de Martin Heidegger e Peter Sloterdijk a respeito do conceito de "espaço interior", evocado pelo poeta praguense Rainer M. Rilke e devedora da noção de "aberto", por ele empregada na oitava das Elegias de Duino. Heidegger compreende o aberto rilkeano em duas acepções: como o ilimitado vazio ao qual o sujeito interpõe representações; e como espaço interior, locus da "existência" (Dasein) no qual repousa a experiência originária de habitar poético no mundo. Sloterdijk percebe uma familiaridade crucial com o serno-mundo heideggeriano na noção de espaço interior, mas com ressalvas: o espaço rilkeano, em oposição ao heideggeriano, se caracteriza como espaço da "en-stase", não da "ek-stase". Isso parece implicar a dissidência com o "aberto" próprio da filosofia heideggeriana, com o qual Heidegger caracteriza a transcendência do Dasein enquanto abertura. De forma afim, Sloterdijk considera necessário interpor, entre o mundo circundante (Umwelt) fechado do animal e o aberto do clarão do ser heideggeriano uma outra instância: a esfera, enquanto espaço de intimidade próprio do humano. Em vista disso, intentamos discutir sobre algumas dessas aproximações e dissidências e em como elas parecem exigir duas posturas antagônicas com relação ao homem, ao animal e à técnica.

Palavras-chave: aberto, espaço interior, Rainer Maria Rilke.

"Com todos os olhos a Criatura / vê o Aberto." (RILKE, 1989, p. 185). A frase enigmática abre a oitava das Elegias de Duíno, do poeta praguense Rainer Maria Rilke, escritas entre 1912 e 1922 durante um período marcado por polos de efervescência elegíaca. A relação do animal, do homem e dos anjos com o aberto (das Offene), o inapreensível e incomensurável, foi tema idiossincrático da poesia rilkeana tardia, retomado como uma das principais chaves de entrada à sua obra poética. Na mesma elegia, aprendemos que, entre o aberto e o nada que a morte presentifica aos entes, há confluência fundamental (ibid.). De Maurice Blanchot, consoante, derivamos que essa dimensão de abertura pura a qual a morte pertence tem sua positividade na constante contemporaneidade com a vida, prenhe por toda sua vigência de seu próprio esgotamento (1987, p. 131). À diferença das bestas e das divindades, para Rilke, os homens convivem com a morte como com um parente distante que nunca veem, e que os acena ao longe, amiúde, sem porém ser percebido, a despeito de seus poucos e raros momentos de vago vislumbre - na infância ou por detrás do amante ou no olhar do animal. Por fora disso, o aberto mantém-se no limite inescrutável, "e de novo se faz mundo"

(RILKE, 1989,

p.

187). 


\section{SEMINÁRIO DE PESQUISA EM CIÊNCIAS HUMANAS - SEPECH \\ Humanidades, Estado e desafios didático-científicos \\ Londrina, 27 a 29 de julho de 2016}

Essas palavras proferidas sobre Rilke suscitam a lembrança de um de seus mais proeminentes leitores: Martin Heidegger, filósofo para quem a morte encontra-se como possibilidade sempre antecipada, e ao mesmo tempo dissimulada, desse ente que nós mesmo somos. Da mesma forma, aquilo que permeia a manifestação do real e que, não se confundindo com a totalidade mesma, provê medida a ela, também é o mesmo que de início e no mais das vezes se retrai-isto é, o ser, em sua constante retração com relação ao mundo manifesto do ente (cf. HEIDEGGER, 2012, p. 39). Não a toa, Rilke é, para Heidegger, seu contemporâneo, o "poeta em tempo indigente" (id. 2002, p. 314) por excelência. É ele quem, em tempos de obscurescimento total da dimensão prímeva do ser em favor da presentificação técnica de todo o real, manifesto como operatividade em virtude da retroalimentação da própria operatividade (ibid. p. 316), mais conseguiu, de maneira poética, evocar a situação do homem frente a um mundo representado que o veda à manifestação mais própria do aberto (ibid. pp. 366-367).

É, contudo, necessário prudência ao tratar da aproximação de Heidegger e Rilke. Para aquele, o poeta dos Sonetos de Orfeu é, ainda, um "metafísico", ou seja, alguém que, preso à inescapável linguagem na qual habita, não pode possuir palavras que o permitam escapar à "condição humana" que ele mesmo denuncia em seus poemas. Nesse sentido, postado no ápice de uma história do esquecimento do ser, levada a cabo desde os tempos gregos e responsável pela metafísica do Ocidente, Rilke é o poeta que, paralelo a Friedrich Nietzsche na filosofia, na leitura heideggeriana, promove os retoques finais do acabamento na história da metafísica (ibid. p. 329). O aberto rilkeano, portanto, não pode se confundir sem ressalvas com o "aberto" ao qual Heidegger alude (ibid. p. 326) sem nunca, porém, fixá-lo em conceito, por se colocar ele mesmo no interior dessa história, e que, portanto, melhor caracteriza o que o filósofo pretende com seu pensamento de espera ao apelo do ser.

Neste trabalho, pretendemos, assim, recorrer à leitura heideggeriana do que viria a ser o aberto de Rilke, noção na qual, para Heidegger, vige uma profunda ambiguidade: por um lado, representa justamente uma dimensão complementar à própria subjetividade que vigora no ser humano enquanto este que dá as costas ao aberto e, portanto, partilha, como negativo, da mesma lógica metafísica que a própria subjetividade (ibid. pp. 327-329); por outro, em contexto outro que não o da Oitava Elegia, e de forma mais alusória que explícita, como "outro nome para o aberto" (ibid. p. 352), é acenado como uma dimensão mais fundamental, "espaço interior do coração", próxima àquilo que Heidegger entenderia como sendo o modo mais próprio de existência do homem e que, manifestação-retração do ser, estaria sob sua guarda (ibid.). Essa aproximação mesma foi levantada pelo filósofo contemporâneo Peter Sloterdijk, para quem o ser-no-mundo heideggeriano e o "espaço interior" rilkeano partilhariam características como duas formas símiles de habitar ontológico (2008, pp. 212-213). Haveria, no entanto, uma diferença fundamental que caracterizaria a dissidência do projeto sloterdijkiano, devedor das formulações fenomenológicas de Heidegger, e que permitiria a Sloterdijk uma visão crítica com relação à obra heideggeriana (ibid.). Pretendemos, pois, ensaiar uma aproximação inicial entre a poesia rilkeana e a ontologia heideggeriana, a fim de melhor compreender a recepção criteriosa de Heidegger por Sloterdijk, tão quanto abrir espaço para outra interpretação filosófica de Rilke que, passando por Heidegger, escape às pretensões do projeto ontológico heideggeriano, na esteira de interpretações não heideggerianas de Nietzsche, como ocorre em Sloterdijk.

Portanto, é necessário retomar brevemente o texto de Heidegger que faz tais 


\section{SEMINÁRIO DE PESQUISA EM CIÊNCIAS HUMANAS - SEPECH \\ Humanidades, Estado e desafios didático-científicos \\ Londrina, 27 a 29 de julho de 2016}

referências ao conceito de aberto em Rilke: Para quê poetas? (2002), integrante da coletânea de textos Caminhos da floresta. Neste texto, vê-se Heidegger questionando se Rilke é um poeta aos moldes hölderlinianos, isto é, um poeta "em tempo indigente" (ibid. p. 314). Para Heidegger, Rilke como que dança beira ao abismo, fitando-o, mais do que o homem comum, e correndo o risco do desamparo-por isso, como um poeta em tempo de pobreza do ser (ibid. pp. 314-316). Mas, também, como um poeta em tempo indigente, Rilke, tal qual Nietzsche, dá voz à metafísica sem, contudo, superá-la, de acordo com Heidegger (ibid. p. 329). Por isso, a noção rilkeana de aberto, para o filósofo, opera em uma inversão com relação ao aberto que o filósofo alemão propõe como originário, isto é, o aberto como alétheia, na dinâmica de velamento e desvelamento de ser e ente (ibid. p. 327).

O primeiro sentido do aberto rilkeano fica evidente já na Oitava Elegia: "Com todos os olhos a Criatura [die Kreatur] / vê o Aberto. Só os nossos parecem / invertidos e todos dispostos ao redor, / como armadilha, em torno de sua livre saída." (RILKE, 1989, p. 185). O animal (die Kreatur) de Rilke tem acesso ao aberto, enquanto ao homem, se faz mundo, ou seja, se interpõe, mediante uma consciência, anteparo mediador de representações ao aberto, tornando este em objeto. O animal, nesse sentido, se encontra inconscientemente "no mundo", arrastado pelo fluxo de feixes irracionais de vontade da natureza, enquanto que o homem se encontra "diante do mundo", apartado deste por seu grau de consciência (HEIDEGGER, 2002, p. 329). O aberto, aqui, aparece então, por um lado, como o face abscôndita daquilo que representa a razão humana, como "totalidade de tudo aquilo que não está restringido" (ibid. p. 326), isto é, espaço puro livre das objetivações restritivas da representação, como "ilimitação que em tudo vigora" (ibid. p. 327) e que está passível de preenchimento pelo representar objetivador, e por outro, como "totalidade dos nexos ilimitados da conexão pura" (ibid.), do qual o homem está apartado e ao qual só o animal responde, como por um processo de desinibição inconsciente.

Heidegger opera uma inversão com relação à elegia—ou rearranja a já inversão rilkeana, como afirma Giorgio Agamben (2002, p. 61): o aberto heideggeriano é justamente onde o ente humano, de início, se encontra, aberto ao ser em seu movimento de retraçao e doação, enquanto o animal se encontra ante uma cegueira com relação ao ente na totalidade, aquém de seu revelamento (ibid. pp. 60-61). Rilke tem por aberto justamente o contrário porque ele, para Heidegger (2002), ele se encontra, junto a Nietzsche, em um momento diametralmente oposto ao momento grego, de assunção do aberto em seu sentido originário (ibid. p. 316). A situação histórica do poeta é posterior à criação do cogito e da subjetividade, bem como das metafísicas vitalistas da Vontade; por isso, a representação do homem de Rilke é, como a de Nietzsche, a representação do ente representador por excelência, como aquele que põe diante de si o mundo e dispõe dele como objeto, instrumento e valor (ibid. p. 327). Apesar de o poeta sofrer a nostalgia de um aberto perdido, só acessível aos animais, ele tem por esse aberto justamente o negativo do mundo representacional do homem: o aberto é o ilimitado formal que permite a restrição da representação e, ao mesmo tempo, é a totalidade da vontade, que constrange o ente na totalidade a um movimento incessante de vontade por ela mesma (ibid. p. 326) - que, na eisegese heideggeriana de Nietzsche, se tornaria "vontade de vontade", como modo de ser próprio do fím da metafísica (id. 2001, p. 70).

No entanto, como afirmamos, no mesmo texto em que faz essas observações, Heidegger compreende que Rilke, por outra via, alude a uma noção de aberto mais 


\section{SEMINÁRIO DE PESQUISA EM CIÊNCIAS HUMANAS - SEPECH \\ Humanidades, Estado e desafios didático-científicos \\ Londrina, 27 a 29 de julho de 2016}

próxima do que intenciona o filósofo. Essa outra forma de aberto aparece em meio a versos improvisados por Rilke em 1924, sem título, em carta à sra. Clara Rilke, ocasião em que o poeta fala sobre o risco do ser exposto na Natureza (isto é, no aberto como concebido na Oitava Elegia) (apud id. 2002, p. 318): "[...] o que por fim nos alberga, / é o nosso desamparo, e que / ao aberto assim o virámos [sic], vendo-o ameaçar [...]". Retomando justamente esses versos (ibid. p. 344), compara-os Heidegger ao famoso fragmento de Patmos, do poeta Friedrich Hölderlin: "Mas onde há perigo / há também salvação." (1991, p. 181) O risco do aberto, aquele que ameaça ao poeta exposto à intempérie, é o risco do lugar do acabamento da metafísica, local onde vige o perigo e onde, também, habita o que salva (HEIDEGGER, 2002, p. 340).

A tese do texto de Heidegger, como um todo, é de que o poeta no tempo indigente é aquele que mais fundo vislumbra o abismo e, assim arriscado, prepara o resgate para o tempo vindouro (ibid. p. 365). O poeta, o mais desamparado e mais exposto às intempéries do ser, é o que possui abrigo, albergue, habitando o mundo de maneira mais própria. Em uma intrincada cadeia argumentativa, o filósofo afirma ser reversão do desamparo ao aberto também o aprofundamento em outra dimensão do aberto, como inversão do afastamento do homem rumo ao aberto na assunção de, se poderia dizer, um aberto "mais originário", mais essencial, isto é, mais próximo de sua proveniência (ibid. p. 351). Essa inversão, que aproxima sobremaneira Rilke de Heidegger, é, para esse último, a negação de uma imanente "lógica da consciência", que visa o interior subjetivo de representações em afastamento do "aberto" como exterior da "coisa em si" e que toma o mundo como cálculo, e a assunção de uma paralela e mais imanente "lógica do coração" (1989, p. 351), inextensa, incalculável e pronta a acolher de modo apropriado o aberto, agora, num sentido mais essencial e próximo do aberto heideggeriano, habitando-o. A essa lógica, que o último verso da Nona Elegia prenuncia (“[...] uma existência [Dasein] incomensurável / desabrocha-me no coração." in RILKE, 1989, p. 197), corresponde o espaço mais interior que o interior da consciência, "espaço interior do coração" (HEIDEGGER, 2002, p. 352), que Rilke chama de "espaço interior do mundo" (Weltinnenraum) em Todas as coisas, ou quase, fazem sinais aos nossos sentidos (id. in 2008 [1914]).

Desse último poema, vale menção os cinco versos abaixo, citados por Sloterdijk em Palácio de cristal, na tradução lusitana de Manuel Resende (ibid.):

Por todos os seres passa o único espaço:

Espaço interior do mundo. Calmas aves

Em nós perpassam. Oh, como quero crescer,

Fito o lá-fora e em mim cresce a árvore.

Em mim o cuidado, e em mim está a casa.

$\mathrm{Na}$ interpretação de Heidegger, é o poeta (como Rilke) aquele que, desamparado, se alberga no espaço interior do mundo e o habita, por retornar à linguagem, único espaço e meio universal, em seu âmbito original—e, nesse texto como em Carta sobre o humanismo (2008, p. 326), a linguagem é "casa do ser" (id. 2002, p. $356)$, lugar de doação originária de medida histórica a um povo. O poeta, o cantor

\footnotetext{
${ }^{1}$ A título de nota, Heidegger faz alusão aqui à contraposição entre René Descartes e Blaise Pascal, respectivamente.
} 


\title{
XI SEMINÁRIO DE PESQUISA EM CIÊNCIAS HUMANAS - SEPECH \\ Humanidades, Estado e desafios didático-científicos \\ Londrina, 27 a 29 de julho de 2016
}

órfico, é aquele que arrisca a linguagem e, por isso, prepara o retorno do ser ao albergarse na linguagem (e albergá-la, cultivando-a e nutrindo-a, sem tentar calculá-la e reduzíla a instrumento) (ibid.). Por isso, diz Rilke no terceiro dos Sonetos a Orfeu: "cantar é existir [Dasein]" (1989, p. 25)—ou, para Heidegger, cantar é "aí-ser" (2002, p. 363), Da-sein, existir na linguagem.

Sloterdijk, por sua vez, resgata o Weltinneraum rilkeano em contexto diverso do de Heidegger, em inusitada aproximação com escritos de Adam Smith sobre o funcionamento do mercado no grande interior do mundo capitalista contemporâneo. Antes de efetuar tal encontro, o filósofo de Esferas disserta rapidamente acerca da noção rilkeana de espaço interior e a compara a de Heidegger (2008, pp. 212-213):

\begin{abstract}
Assinalemos que o poeta confia à preposição “em" [in] a missão invulgar de confirmar o eu [grifo nosso] como recipiente integral ou lugar universal-em oposição direta à análise do ser-em, feita por Heidegger em Ser e tempo, 1927, onde o "em" é apresentado como expressão de posição da ek-sistência, isto é, do estar-mantido no exterior em direção ao aberto. Poderíamos marcar esta oposição com ajuda das expressões en-stase e ek-stase.
\end{abstract}

Nesse trecho, duas coisas precisam ser explicitadas: primeiramente, Sloterdijk interpreta o Weltinnenraum rilkeano de forma símile à do ser-no-mundo heideggeriano - é preciso desconsiderar por ora o "eu" enfatizado da citação. Não adentrando nas querelas entre "primeiro" e "segundo" Heidegger, vale a nota de que a noção de "habitar" na obra heideggeriana mantém-se como relação essencial e originária com o ser, transviada na história da tradição por via do esquecimento do ser (sobre isso, cf. "Construir, habitar, pensar" in 2001, pp. 125-141). Portanto, tanto o serno-mundo de Ser e tempo como o ente que habita a linguagem da obra tardia assemelham-se a esse ente que, mais do que posto indiferenciadamente em um espaço abstrato, habita e se demora em um lugar (mundo, linguagem) que lhe é familiar e hodierno, em relação fundamental com o próprio ser e com o ser em geral-Martin Kusch (1989), por exemplo, fala que a linguagem em Heidegger é "meio universal", de modo parecido com a menção de Sloterdijk ao Weltinnenraum.

A oposição a que Sloterdijk faz menção, segundo aspecto a ser exposto aquiconsiderando-se, agora, nossa ênfase no "eu" da citação-, refere-se à tensão entre interior e exterior na relação entre Heidegger e Rilke. O último pensa o "eu" como "casa" e, portanto, só no interior desse "eu" é que se habita no mundo como um Dasein, uma existência própria, um, poderiamos inclinar-nos a dizer, "ser-no-espaço-interiordo-mundo"- $\mathrm{e}$, portanto, somente, do sentido que o aberto heideggeriano assume, a acepção de aberto como lugar habitado; ainda assim, no extremo oposto, o ser-nomundo heideggeriano é aquele, também, que está investido na abertura total do ser, em seu clarão que, mesmo não se confundindo com o exterior puro da extensionalidade abstrata, ainda é "casa" tão gigantesca quanto um mundo histórico, uma linguagem.

O que é problemático disso? Para Sloterdijk, a noção de habitar que assume de Heidegger (com ressonâncias de Maurice Merleau-Ponty e Gaston Bachelard; cf. 2008, pp. 120, 213) é sempre própria de um interior. Habita-se um lugar habitual, dentro de limites, uma "casa". O problema em Heidegger é que, tendo-se esvaziado qualquer 


\section{SEMINÁRIO DE PESQUISA EM CIÊNCIAS HUMANAS - SEPECH \\ Humanidades, Estado e desafios didático-científicos \\ Londrina, 27 a 29 de julho de 2016}

forma de interioridade na crítica à metafísica, a "casa do ser", sendo o mundo/linguagem, é um gigantesco exterior (id. 2014a, p. 560) — que, não podendo ser confundido sem ressalvas com o Weltinnenraum rilkeano do "eu", não admite interioridade. No exterior, "a diferença entre o habitar e a exploração nunca é mais clara." (id. 2008, p. 121) Donde deriva-se que, verso ao exterior absoluto do ser, não há cesura com a possibilidade de que tudo se torne recurso a ser explorado, impessoalidade formatadora, totalidade de representação subjetiva ou imagem científica de mundo (ibid.); ela se torna quase que inescapável, como ocorre com a história mesma da metafísica em Heidegger, prenhe de niilismo. Diante da imensidão do ser, só resta como postura reativa, de acordo com Sloterdijk, o provincianismo, a solidão e a passividade do Dasein heideggeriano, ensimesmado frente ao imenso (ibid. p. 122).

Por isso, Sloterdijk (2014a, pp. 305-312) advoga por uma retomada dos parágrafos anteriores ao $\$ 24$ de Ser e tempo (HEIDEGGER, 2012), quando a investigação acerca da espacialidade do Dasein ainda não havia tropeçado no fenômeno do outro impessoal (das Man), que "não é coabitante de uma esfera comum [...], de uma 'cultura' ou de uma vida partilhada, mas um elemento indiferenciado de circunstâncias exteriores mal ou bem-vindas" (SLOTERDIJK, 2008, p. 121) e, por isso, suspeitos ou inimigos em potencial. A própria posição heideggeriana com relação ao modo de ser da técnica contemporânea (Gestell) derivaria desse "tropeço".

Assim, Sloterdijk retoma o habitar heideggeriano, mas amparado em um pano de fundo nietzscheano com relação à animalidade precedente do homem: de forma análoga a Nietzsche (2008), no qual o homem não passa de um animal que, falho em ser animal, desenvolve estratégias gregárias - dentre elas, a linguagem - para sobreviver e se isolar do absoluto exterior, também o homem sloterdijkiano tem de, primeiramente, sair de seu estágio pré-humano, animal, e progressivamente, em conjunto, construir-se paulatinamente por meio de artifícios de autogenia até o ponto em que constroi o que hoje conhecemos por "cultura humana" (SLOTERDIJK, 2011, p. 114).

Em vista da observação de que o "aberto" exterior é arriscado demais para um animal falho de sua animalidade ${ }^{2}$, o ser-no-mundo, apesar de situar a questão do habitar, se torna problemático enquanto tal (ibid. p. 113). Deve haver, para Sloterdijk, algo entre o mundo circundante (Umwelt) do animal, restrito ao conjunto de suas desinibições e, para elas, "cego", anterior à manifestação do ser, e o exterior da clareira do ser, uma dimensão intermediária, interior mas, também, não individual, visto que o ser humano só pode ser produto autógeno em gregariedade (ibid.).

E justamente para isso é que o filósofo articula o conceito de "esfera", e nisso a noção de "en-stase" vem a calhar como um exemplo_-desde que empreendida devida compreensão do "eu" não como sujeito individual apartado de mundo. Para Sloterdijk (2008, p. 213), é Bachelard, em A poética do espaço (1993), quem clarifica melhor a característica mais própria do espaço interior rilkeano ao articular uma fenomenologia das experiências poéticas primevas de intimidade do que ele considera a verdadeira "casa de ser" (maison d'être), anterior mesmo à linguagem (ibid. pp. 72-73).

A intimidade do espaço da casa indica já não a ascepcia do estado teórico ou contemplativo em um espaço homogêneo, desqualificado, mas a própria noção de

\footnotetext{
${ }^{2}$ Mas talvez não para os animais figurados nos poemas de Rilke, os quais, investidos de um mundo circundante (Umwelt) como numa "jaula natural", ainda poderiam se manter albergados por suas próprias desinibições das intempéries do exterior. Sobre a relação (factual e teórica) entre o criador da noção de Umwelt e o poeta, cf. WINTHROP-YOUNG in UEXKÜLL, 2010, pp. 229-235.
} 


\section{SEMINÁRIO DE PESQUISA EM CIÊNCIAS HUMANAS - SEPECH \\ Humanidades, Estado e desafios didático-científicos \\ Londrina, 27 a 29 de julho de 2016}

reverberação de sentido e atração entre os polos da casa - a análise desses polos, Bachelard batiza como "topofilia" e, neles, pensa espaços, objetos ou pessoas que habitam a casa e funcionam como motrizes afetivas e mnemóticas. A formação de sentido do eu passa pela formação de sentido da casa, isto é, do espaço de intimidade, e isso antes mesmo de ganhar forma por uma linguagem já dada (ibid. p. 31).

Com relação à Weltinnenraum, atribui-lhe Bachelard a experiência de imensidão, na conjugação do espaço da intimidade e do espaço do mundo, enquanto espaço envolvente. O "eu" do poema não pode ser o sujeito singular, desprovido de lugar, porque o interior a que o "eu" se refere é a casa mesma, isto é, a intimidade mesma. (ibid. p. 207) Na esteira dessa interpretação, Sloterdijk atribui à en-stase rilkeana o "modo de experiência do mundo que é típico do 'narcisismo' primário" (2008, p. 212), não enquanto autorreferência, mas sim como experiência primeira do feto frente ao outro ainda não objetivo que lhe conforma no útero (sobre isso, cf. id. Esferas I, 2014a, cap. 5) e que, transposto a contextos posteriores ao nascimento (como na casa literal da infância), molda "o ambiente presente e o seu prolongamento imaginário [...] a partir das experiências de calor e nas suposições semânticas de um espírito ágil, exaltado e não diferenciado." (id. 2008, p. 212). O que ocorre, então, com o sentimento de "coerência oceânica" (ibid.) da Weltinnenraum é a "repetição da sensação fetal numa cena exterior." (ibid.)

Pois bem, a análise microesferológica realizada em Esferas I (2014a) e que assenta as categorias básicas do conceito de esfera sloterdijkiano é justamente, como supracitado, a análise do espaço uterino, no qual já ocorre a tríplice ressonância de uma esfera básica, modular, como medium por excelência do habitar humano: "a convvivência de algo com algo em algo" (ibid. p. 487, trad. nossa) — o feto com a placenta dentro do útero materno, "espaço interior da mãe absoluta" (ibid. p. 485, trad. nossa) como modelo da imanência de todas suas "metaforizações posteriores ao parto" (ibid. p. 486). Toda esfera, para Sloterdijk, pode ser definida dessa forma. A esfera, portanto, é sempre um topos imunológico de ressonância de dois ou mais polos (leia-se "intimidade") que cria uma diferença fundamental entre um interior de sentido e um exterior sem, contudo, torná-la anteparo intransponível (ibid. p. 487) - a analogia da célula funciona bem, com sua membrana semipermeável. Não se fala mais aqui, sendo assim, no sujeito envolvido em seu globo monádico de representações, mas isolado da coisa-em-si; não se está em uma esfera individual, mas em esferas de relações fortes, no trânsito entre microesferas (como o útero ou a casa) e macroesferas (como uma linguagem, uma comunidade ou uma pátria), em relação de pressão e osmoze com o exterior (ibid.). Transmuta-se, enfim, o ser-no-mundo, que joga o habitante ao imenso (ibid. p. 561), em ser-em-esferas, cambiando nas imunologias próprias das experiências de intimidade (ibid. p. 487).

Percebe-se que, de maneira diversa a de Heidegger, Sloterdijk considera na experiência interior de Rilke não uma analogia ao ser-no-mundo, falha apenas por sua dívida com uma metafísica de porte nietzscheano-inclusive porque as considerações sobre Nietzsche acerca do homem e do animal são decisivas, ainda que nem sempre evidentes, na construção argumentativa sloterdijkiana. Para Sloterdijk, a poética do espaço deve muito a Rilke (ibid., p. 70), e é possível supor uma chave de leitura de Rilke que, passando por Heidegger, seja seletiva com algumas de suas interpretaçõesseja na imanência mesma de suas questões, seja na interpretação que faz de Rilke à luz 


\section{SEMINÁRIO DE PESQUISA EM CIÊNCIAS HUMANAS - SEPECH \\ Humanidades, Estado e desafios didático-científicos \\ Londrina, 27 a 29 de julho de 2016}

da interpretação sui generis que faz de Nietzsche. Com tal procedimento, algumas das questões caras a Rilke, como o estatuto ontológico do animal frente ao aberto, poderiam ser retomadas das leituras mais canônicas em sua positividade, ao mesmo tempo em que associadas e articuladas com algumas noções ontológicas do pensador alemão sobre a existência, o habitar, o ser e a morte que parecem complementares às do poeta.

Ainda sobre isso, parece necessário, por fim, alguns apontamentos marginais, apesar de findo o artigo. Eles surgem em torno da hipótese de que a leitura heideggeriana de Rilke esteja maculada de sua interpretação do opus nietzscheano como corolária do acabamento da metafísica. Poderíamos formular, sobre isso, uma questão a ser pensada: o aberto da Oitava Elegia não surgiria como faceta do mesmo "único espaço" do Weltinnenraum? A questão surge, na verdade, para pôr em evidência o problema da animalidade humana. $\mathrm{O}$ aberto aparece justamente como aquilo do qual é acessível pelo olhar animal, e que por vezes se faz presente de forma efêmera na intensidade dos amantes em fluxo ou na inocência ignóbil da criança. Em Heidegger, a animalidade do homem é rebaixada, em virtude de sua proximidade com o ser-com os deuses. Porém, algumas interpretações apontam a proximidade entre animais e deuses (e anjos) na poesia rilkeana, ao passo que o homem, opondo a si um mundo, estaria afastado até mesmo dos deuses (cf. p.ex. MAROVICH, 2014, pp. 134-145). A nostalgia rilkeana pelo "paraíso perdido" do aberto assemelhar-se-ía, então, àquela pelo "espaço interior", como um tipo de imanência da qual parece partilhar Sloterdijk (2014a) com Agamben (2015) e Gilles Deleuze (2002), e que lembra justamente a visão nietzscheana do homem como um animal criativo em virtude de sua falta enquanto animal. Pareceria então que, a partir de Rilke e Nietzsche, poderia se pensar em um vínculo forte entre animalidade e imanência que permitisse pensar a imanência do ser humano como vinculada a sua própria animalidade, e que faria com que a investigação sobre tal, com relação a importantes questões da contemporaneidade, se fizesse de suma importância. ${ }^{3}$

\section{REFERÊNCIAS}

AGAMBEN, Giorgio. "A imanência absoluta". In: . A potência do pensamento: ensaios e conferências. Trad. de Antônio Guerreiro. Belo Horizonte: Autêntica, 2015.

L'aperto: l'uomo e l'animale. Torino: Bollati Boringhieri, 2002.

BACHELARD, Gaston. A poética do espaço. Trad. de Antonio de Padua Danesi. São Paulo: Martins Fontes, 1993.

BLANCHOT, Maurice. O espaço literário. Rio de Janeiro: Rocco, 1987.

DELEUZE, Gilles. "Imanência: uma vida." Educação e realidade. Trad. de Tomaz Tadeu. Porto Alegre, vol. 27, n.2, pp. 10-18, jul./dez. 2002.

\footnotetext{
3 Como exemplo dessa confluência da contemporaneidade com a animalidade, além das obras de Agamben, Deleuze e Sloterdijk, que pensam problemas concernentes ao capitalismo, à democracia, à exclusão, ao controle, à biopolítica etc. cf. o artigo, publicado em 2014, de Paul Beatriz Preciado, intitulado "O feminismo não é um humanismo", e que questiona o humanismo a partir do "animalismo" como "um feminismo dilatado e não antropocêntrico." (2014)
} 


\section{SEMINÁRIO DE PESQUISA EM CIÊNCIAS HUMANAS - SEPECH \\ Humanidades, Estado e desafios didático-científicos \\ Londrina, 27 a 29 de julho de 2016}

HEIDEGGER, Martin. Ensaios e conferências. 2a ed. Trad. de Emmanuel C. Leão, Gilvan Fogel e Márcia S. C. Schuback. Petrópolis: Vozes, 2001.

. Marcas do caminho. Trad. de Enio P. Giachini e Ernildo Stein. Petrópolis: Vozes, 2008.

. Ser e tempo. Trad., org., notas etc. de Fausto Castilho. Campinas: Unicamp; Petrópolis: Vozes, 2012. (Col. "Multilíngues de Filosofia Unicamp")

. "Para quê poetas?". In: . Caminhos da floresta. Trad. de Bernhard Sylla e Vitor Moura. Coimbra: Fundação Calouste Gulbenkian, 2002.

HÖLDERLIN, Friedrich. Poemas. Trad. de José Paulo Paes. São Paulo: Companhia das Letras, 1991.

KUSCH, Martin. Language as calculus versus language as universal medium: a study on Husserl, Heidegger and Gadamer. Dordrecht: Kluwer Academic Publishers, 1989.

MAROVICH, Beatrice. "Little bird in my praying hands: Rainer Maria Rilke and God's animal body". In: MOORE, Stephen D (ed.). Divinanimality: animal theory, creaturely theology. Nova York: Fordham University Press, 2014, pp. 134-145.

NIETZSCHE, Friedrich. Sobre a verdade e a mentira. Trad. de Fernando de M. Barros. São Paulo: Hedra, 2008.

PRECIADO, Paul B. "O feminismo não é um humanismo". O povo, trad. de Charles Feitosa, $\quad$ Fortaleza, 2014. Disponível em $<$ http://www.opovo.com.br/app/colunas/filosofiapop/2014/11/24/noticiasfilosofiapop,33 52134/o-feminismo-nao-e-um-humanismo.shtml>, acesso em 13 fev. 2016.

RILKE, Rainer Maria. Sonetos a Orfeu; Elegias de Duíno. Edição bilíngue, trad. de Emmanuel Carneiro Leão. Petrópolis: Vozes, 1989.

SLOTERDIJK, Peter. Esferas I: Burbujas (Microsferologia). Trad. de Isidoro Reguera. Madrid: Siruela, 2014a, v.1.

. Esferas III: Espumas (Esferología plural). Trad. de Isidoro Reguera. Madrid: Siruela, 2014b, v.3.

. Palácio de cristal: para uma teoria filosófica da globalização. Trad. de Manuel Resende. Lisboa: Relógio D’Água, 2008.

. Sin salvación: tras las huellas de Heidegger. Trad. de Joaquín Chamorro Mielke. Madrid: Akal, 2011.

UEXKÜLL, Jakob v. A foray into the world of animals and humans; $A$ theory of meaning. Trad. por Joseph D. O’Neil. Posfácio de Geoffrey Winthrop-Young. 
XI SEMINÁRIO DE PESQUISA EM CIÊNCIAS HUMANAS - SEPECH

Humanidades, Estado e desafios didático-científicos

Londrina, 27 a 29 de julho de 2016

Minnesota: University of Minnesota Press, 2010. 